\title{
Comprehensive analysis of circulating adipokines and hsCRP association with cardiovascular disease risk factors and metabolic syndrome in Arabs
}

\author{
Mohamed Abu-Farha, Kazem Behbehani and Naser Elkum*
}

\begin{abstract}
Background: Cardiovascular diseases (CVD) are a leading cause of death worldwide including the Middle East. This is caused in part by the dysregulation of adipose tissue leading to increased production of pro-inflammatory adipokines and reduction in cardio-protective adipokines such as adiponectin. Ethnicity has been recognized as a major factor in the association between CVD risk factors and the different circulating adipokines. In this study, for the first time, the relationship between traditional cardiovascular risk factors, Metabolic Syndrome (MetS) and circulating level of adipokines in Arab ethnicity was investigated.
\end{abstract}

Methods: We conducted a population-based cross-sectional survey on 379 adult Arab participants living in Kuwait. Traditional cardiovascular risk factors such as blood pressure (BP), low density lipoprotein (LDL) and triglyceride (TG) were measured. Plasma levels of circulating Leptin, Plasminogen Activator Inhibitor (PAl-1) visfatin, adiponectin, resistin and adipsin were assessed using the multiplexing immunobead-based assay.

Results: Circulating levels of High sensitivity C-Reactive Protein (hsCRP), Leptin, PAl-1 and adiponectin were significantly higher in Arab women than men ( $p$ 0.0001). In multi-variate analysis, the homeostasis model assessment-insulin resistance (HOMA-IR) and body mass index (BMI) showed strong association with most of the biomarkers $(p<0.05)$. HsCRP showed significant association with all risk factors $(p<0.05)$. Leptin, PAl-1 and adipsin showed significant positive correlation with BMI, unlike adiponectin which showed inverse correlation $(p<0.05)$. Subjects in the highest tertile of leptin, PAl-1 and hsCRP had higher odds of having Metabolic Syndrome (MetS) (odd ratio [OR] = 3.02, 95\% confidence interval $[\mathrm{Cl}]=1.47-6.19)$ and $(\mathrm{OR}=2.52,95 \% \mathrm{Cl}=1.45-4.35),(\mathrm{OR}=4.26,95 \% \mathrm{Cl}=2.39-7.59)$ respectively. On the other hand subjects with highest tertile of adiponectin had lower odds of having MetS $(\mathrm{OR}=0.22,95 \% \mathrm{Cl}=0.12-0.40)$. Leptin, PAl-1 and hsCRP showed significant positive association with increased MetS components (P-trend $<0.05$ ), while adiponectin was negatively associated with increased MetS components (P-trend $<0.0001$ ).

Conclusion: Our results show positive association between hsCRP, leptin, PAl-1 with increased MetS components and increase the odds of having MetS. Adiponectin on the other hand showed inverse correlation with MetS components and associated with reduction in MetS. Overall, our data highlights the significant clinical value these markers have in MetS especially hsCRP which can be used as good marker of low grade inflammation in Arabs.

Keywords: Adipokine, Arab, Metabolic syndrome, Cardiometabolic risk factors, Lipid profile, hsCRP, Leptin, Adiponectin, Visfatin, Resistin, Adipsin, Low grade inflammation

* Correspondence: nelkum@hotmail.com

Dasman Diabetes Institute, P.O.Box 1180, Dasman 15462, Kuwait 


\section{Introduction}

CVD are one of the leading causes of mortality worldwide [1]. Due to the increase in obesity and MetS, CVD mortality and morbidity are expected to increase even higher posing a huge risk to public health and health care systems around the globe [1]. CVD include cardiomyopathy, cardiac dysrhythmias, myocarditis, myocardial infarction, hypertension and atherosclerosis [2]. A number of risk factors have been identified to be associated with CVD such as hypertension, obesity, smoking, life style, hyperlipidaemia, Type 2 Diabetes (T2D) and MetS [2]. MetS is a cluster of metabolic risk factors that has been shown to cause a two fold increase in cardiovascular outcomes and a 1.5 fold increase in all-cause mortality [3-5]. Central obesity, dyslipidemia, elevated blood pressure; elevated fasting glucose and insulin resistance are the most pivotal components of MetS [6]. MetS is also characterized by a chronic low grade inflammation state which can explain the increased CVD and T2D risk [7]. MetS is also characterized by a low grade inflammation with increased hsCRP level. HsCRP is a marker of low grade inflammation which was shown in many studies to be higher in subjects with MetS and it associates with increased risk of CVD and T2D [7].

The association between MetS, obesity, T2D and CVD is intertwined due to their role in the disruption of homeostasis of important factors such as inflammatory markers and stress related markers in addition to other adipokines produced by adipose tissue [2]. Adipose tissue is an organ that was originally thought to be simply a storage organ for triacylglycerol [8]. Recently, it has been recognized as a metabolically active endocrine organ that affects various biological processes such as energy homeostasis, feeding, immunity and glucose and lipid metabolism amongst others [9]. The main cell types residing in adipose tissues are adipocytes, preadipocytes, fibroblasts, endothelial cells, and immune cells such as macrophages and lymphocytes [9]. Disruption of normal adipose tissue function; as shown with increased obesity; leads to the production and release of proinflammatory, atherogenic, and diabetogenic agents [9]. Consequently, various adipokines such as TNF- $\alpha$, IL-6, leptin, adiponectin, visfatin, PAI-1 and others are secreted to the blood stream $[8,10]$. The association between the different adipokines and CVD risk factors has been under investigation to understand their role in cardio-metabolic risk [9]. Adiponectin and PAI-1 for example, are two adipokines with opposing effects on CVD, where adiponectin is thought to be cardio-protective [11] and PAI-1 is atherogenic [12].

Ethnicity has been suggested as a major factor in determining expression level of various metabolic markers and their association with CVD, T2D and MetS [13-17]. Association between adipokines and CVD risk factors and MetS are not very well studied in the Arab population [18]. This prompted our effort to understand the relationship between CVD risk factors and MetS with hsCRP and a group of adipokins in this population. We present population based cross-sectional study in an Arab population living in Kuwait that look at the association between MetS and CVD risk factors such as high fasting blood glucose, high LDL, BMI with a number of adipokines such as leptin, PAI-1 and adiponectin in addition to hsCRP. We also aim to identify markers that can independently associate with MetS and could potentially serve as good prognostic marker for CVD risk in Arab ethnicity.

\section{Materials and methods \\ Study participants}

This is a cross-sectional population-based survey undertaken on 379 adult Arab expatriates living in the state of Kuwait. According to the 2011 census, $67.7 \%$ of the Kuwait population is expatriates hailing mostly from Arab countries, Indian subcontinent and South East Asia. Subjects originating from Arab countries such as Egypt, Syria, Lebanon, Palestine, Jordan and/or Arab gulf countries were classified as Arabs. Subjects were selected randomly from the computerized register of the Public Authority of Civil Information. Participants with history of CVD were excluded from the study. The study conformed to the principles outlined in the Declaration of Helsinki and was approved by the institutional Ethical Review Committee at Dasman Diabetes Institute. An informed written consent was obtained from all the participants before their enrolment in the study. This study was carried out between June 2011 and August 2012.

\section{Anthropometric and physical measurements}

Physical and anthropometric measurements included body weight, height, waist circumference (WC) as well as systolic blood pressure (SBP) and diastolic blood pressure (DBP). Height and weight were measured, with participants wearing light indoor clothing and bear-footed using calibrated portable electronic weighing scales and portable inflexible height measuring bars. Waist circumference was measured using constant tension tape at the end of a normal expiration, with arms relaxed at the sides, the highest point of the iliac crest and the mid-axillary line. BP was measured with Omron HEM-907XL Digital sphygmomanometer. An average of $3 \mathrm{BP}$ readings, with 5 to 10 minutes rest between each, was obtained. BMI was calculated using the standard BMI formula: body weight (in kilograms) divided by height (in meters squared).

\section{Laboratory measurements}

Blood samples were obtained after an overnight fasting for at least 10 hours and analyzed for fasting glucose, 
glycated haemoglobin A1c (HbA1c), fasting insulin, and lipid profiles that included TG, total cholesterol (TC), LDL, and high-density lipoprotein (HDL). Glucose and lipid profiles were measured on the Siemens Dimension RXL chemistry analyzer (Diamond Diagnostics, Holliston, MA). HbA1c was determined using the Variant ${ }^{\mathrm{TM}}$ device (BioRad, Hercules, CA). All laboratory tests were performed by certified nurses and technicians at the clinical laboratories of DDI, using the Ministry of Health approved methods and quality standards. Insulin resistance was calculated using HOMA-IR formula: fasting blood glucose (FBG) $(\mathrm{mmol} / \mathrm{L}) \mathrm{x}$ fasting Insulin $(\mathrm{mU} / \mathrm{L}) / 22.5$.

To measure adipokines, blood was drawn into EDTA tubes. Plasma was obtained after centrifugation, aliquoted and then stored at $-80^{\circ} \mathrm{C}$. Plasma levels of adipokines were assessed using the multiplexing immunobead array platform (Luminex, Austin, TX). We used the Human Diabetes 10-Plex kit consisting of leptin, PAI-1, resistin, and visfatin) and 2-Plex kit consisting of adiponectin and adipsin (BioRad, Hercules, CA).). Experimental data was processed with Bio-Plex manager software version 6 (Bio-Rad, Hercules, CA) using five-parametric curve fitting. HsCRP secreted level was measured using ELISA kit (Biovendor, USA). All the above mentioned assays were carried out according the manufacturers procedures.

The current recommendations and updated guidelines for the definition, diagnosis and classification of MetS, published by the International Diabetes Federation (IDF), were used [19]. MetS was defined by abdominal obesity and at least two of: fasting blood glucose values $\geq 5.6 \mathrm{mmol} / \mathrm{L}$, hypertension was defined as $\mathrm{BP} \geq 130 / 85 \mathrm{mmHg}$, under treatment, or a self-report of previously diagnosed hypertension. Hypertriglyceridemia as $\geq 1.7 \mathrm{mmol} / \mathrm{L}$ and low HDL cholesterol as $<1.03 \mathrm{mmol} / \mathrm{L}$ in men and $<1.29 \mathrm{mmol} / \mathrm{L}$ in women. BMI between 18.5 and 24.9 was considered normal, 25 to 29.9 , overweight, and equal to or higher than 30 , was considered obese. Cutoffs for central obesity were adopted from IDF; they were defined based on race and gender. In our population $\mathrm{WC} \geq 94 \mathrm{~cm}$ in men and $\geq 80 \mathrm{~cm}$ in women was used.

\section{Statistical analysis}

Comparisons between clinical and biochemical profiles between gender were made by Student's t-test or Wilcoxon test for non-parametric analyses in variables with nonnormal distribution. To assess difference in categorical variables between male and female, Chi-Squared test was used. Spearman's correlation coefficients were estimated to determine associations between adipokine concentrations and anthropometric measurements and biochemical variables. Subjects were classified into tertiles based on their circulating adipokines levels in the overall population. Multivariable logistic regression analysis was performed to estimate odds ratios (ORs) adjusted for covariates and to assess the predictive effect of adipokines on risk for developing MetS. All data are reported as Mean \pm Standard Deviation (SD) and range, unless stated otherwise. Research Electronic Data Capture (REDCap) was used for data collections and data management. All statistical assessments were two-sided and considered to be significant when $P$-value $<0.05$. All analyses were performed using SAS (version 9.2; SAS Institute, Cary, NC).

\section{Results}

379 subjects ( $\geq 20$ years of age) were interviewed and included in this analysis, of which $50.9 \%$ were female. Women and men had similar mean age $(44.1 \pm 11.9$ years \& $44.9 \pm 11.5$ years respectively). Generally, the men had higher SBP and DBP, FBG, HbA1c, Triglyceride and lower BMI, total cholesterol, HDL, and LDL than women, as shown in Table 1. Overall, women presented with higher circulating levels of hsCRP, leptin, PAI-1, resistin, and adiponectin. There are insignificant difference in visfatin, and adipsin between women and men.

Age-sex adjusted Spearman partial correlations, Table 2, showed that PAI-1 and adiponectin were significantly associated with most CVD risk factors. HsCRP showed most association as it associated with all risk factors showing strongest association with BMI and $\mathrm{WC}\left(\mathrm{R}^{2}=0.50\right.$, $\mathrm{p}<0.0001)$ and $\left(\mathrm{R}^{2}=0.46, \mathrm{p}<0.0001\right)$ respectively. PAI-1 showed positive correlation with BMI, WC, SBP, DBP in addition to HOMA-IR and TG and negative correlation with HDL ( $\mathrm{p}$ 0.05). Resistin and adiponectin on the other hand showed an opposite pattern of correlation. Resistin showed negative correlation with SBP, DBP, FBG and HOMA-IR $(\mathrm{p}<0.05)$. Adiponectin showed negative correlation with BMI, WC, SBP, FBG, HOMA-IR, TG and positive correlation with HDL $(\mathrm{p}<0.05)$. Increased level of visfatin was associated with increased FBG, HOMA-IR, TCHL, LDL, and TG and decreased HDL level $(\mathrm{p}<0.05)$. Similarly plasma leptin level was significantly associated with BMI, WC as well as HOMA-IR $(\mathrm{p}<0.0001)$, Table 3 .

After adjusting for age and gender subjects in the highest tertile of leptin, PAI-1and hsCRP had higher odds of having MetS $(\mathrm{OR}=3.02,95 \% \mathrm{CI}=1.47-6.19)$ $(P$-trend $=0.0029),(\mathrm{OR}=2.52,95 \% \mathrm{CI}=1.45-4.35)$ $(P$-trend $=0.0037)(\mathrm{OR}=4.26,95 \% \mathrm{CI}=2.39-7.59)$ $(P$-trend $<0.0001)$ respectively. Subjects in the highest tertile of adiponectin had lower odds of having MetS $(\mathrm{OR}=0.22,95 \% \mathrm{CI}=0.12-0.40)(P$-trend $<0.0001)$. On the other hand, subjects in the highest tertiles of resistin, adipsin and visfatin did not show any significant association with MetS (Table 3). Age-gender adjusted least square means of leptin, PAI-1, hsCRP and adiponectin concentrations showed significant association 
Table 1 Clinical and Socio-demographic characteristics of Arab population

\begin{tabular}{|c|c|c|c|c|}
\hline Characteristics & All $(n=379)$ mean \pm SD & Female $(n=193)$ mean \pm SD & Male $(n=186)$ mean \pm SD & $P$-value \\
\hline Age (years) & $44.4 \pm 11.7$ & $44.1 \pm 11.9$ & $44.9 \pm 11.5$ & 0.5109 \\
\hline BMI $\left(\mathrm{kg} / \mathrm{m}^{2}\right)$ & $31.9 \pm 6.4$ & $33.2 \pm 6.7$ & $30.5 \pm 5.8$ & $<0.0001$ \\
\hline WC $(\mathrm{cm})$ & $101.0 \pm 14.3$ & $99.3 \pm 14.3$ & $102.8 \pm 14.1$ & 0.0153 \\
\hline $\mathrm{SBP}(\mathrm{mmHg})$ & $129.9 \pm 19.8$ & $124.8 \pm 19.6$ & $135.1 \pm 18.5$ & $<0.0001$ \\
\hline $\mathrm{DBP}(\mathrm{mmHg})$ & $78.3 \pm 12.5$ & $76.9 \pm 12.6$ & $79.8 \pm 12.3$ & 0.0252 \\
\hline $\mathrm{FBG}(\mathrm{mmol} / \mathrm{L})$ & $6.2 \pm 3.02$ & $5.9 \pm 2.5$ & $6.6 \pm 3.5$ & 0.0424 \\
\hline $\mathrm{HbA1c}(\%)$ & $6.1 \pm 1.8$ & $5.7 \pm 1.4$ & $6.5 \pm 2.0$ & $<0.0001$ \\
\hline HOMA-IR & $3.3 \pm 3.9$ & $3.4 \pm 4.7$ & $3.1 \pm 3.0$ & 0.4486 \\
\hline $\mathrm{TC}(\mathrm{mmol} / \mathrm{L})$ & $5.2 \pm 1.1$ & $5.3 \pm 1.1$ & $5.1 \pm 1.2$ & 0.0353 \\
\hline $\mathrm{TG}(\mathrm{mmol} / \mathrm{L})$ & $1.7 \pm 1.2$ & $1.5 \pm 0.8$ & $1.9 \pm 1.4$ & 0.0045 \\
\hline HDL cholesterol (mmol/L) & $1.1 \pm 0.4$ & $1.3 \pm 0.4$ & $0.99 \pm 0.2$ & $<0.0001$ \\
\hline LDL cholesterol (mmol/L) & $3.3 \pm 1.0$ & $3.4 \pm 1.0$ & $3.3 \pm 1.0$ & 0.2305 \\
\hline Leptin (ng/mL) & $4.76(0.20-41.6)$ & $8.35(1.1-41.6)$ & $2.57(0.20-25.6)$ & $<0.0001$ \\
\hline PAl-1 (ng/mL) & $6.87(1.06-29.3)$ & 7.38(1.4-29.3) & $5.94(1.06-19.0)$ & $<0.0001$ \\
\hline Adiponectin $(\mu \mathrm{g} / \mathrm{mL})$ & $12.9(1.86-152.1)$ & 15.6(1.86-80.07) & 10.6(2.20-152.1) & $<0.0001$ \\
\hline Visfatin (ng/mL) & $2.96(0.28-179.2)$ & $3.01(0.30-14.9)$ & $2.9(0.28-179.2)$ & 0.6966 \\
\hline Adipsin $(\mu \mathrm{g} / \mathrm{mL})$ & $1.46(0.01-7.5)$ & $1.46(0.48-7.5)$ & $1.46(0.01-5.02)$ & 0.4050 \\
\hline Resistin $(\mathrm{ng} / \mathrm{mL})$ & $2.82(0.43-13.4)$ & $3.01(0.43-12.6)$ & $2.46(0.56-13.4)$ & 0.0002 \\
\hline hsCRP $(\mu \mathrm{g} / \mathrm{mL})$ & $2.82(0.01-21.9)$ & $4.53(0.01-21.9)$ & $2.10(0.01-18.2)$ & $<0.0001$ \\
\hline
\end{tabular}

BMI, body mass index; BP, blood pressure; HDL, high-density lipoprotein; FBG, fasting blood glucose; LDL, low-density lipoprotein.

Results are reported as Mean \pm SD except for non-normally distributed metabolic markers that are presented as Median (range).

with increasing number of MetS components (Figure 1). Increased leptin, PAI-1 and hsCRP plasma level was directly associated with increased number of MetS $(P$-trend $<0.05)$. Adiponectin showed opposite effects as it was inversely associated to increased number of MetS in this population $(P$-trend $<0.0001)$.

\section{Discussion}

The main objective of the current study was to identify metabolic markers that are associated with traditional cardiovascular disease risk factors and MetS in Arab population. Our study showed sexual dimorphism in plasma level of leptin, PAI-1, hsCRP, resistin and adiponectin with women showing higher levels of these metabolic markers in Arabs. hsCRP showed significant positive correlation with all risk factors except for HDL where it was inversely associated. Leptin, PAI-1 and adipsin showed positive correlation with BMI. Visfatin level was not associated BMI level unlike other adipokines. Adiponectin showed highest association with CVD risk factors as it negatively associated with age, BMI, sex, SBP, HOMA-IR and LDL. It was also negatively associated with increased odds of MetS and increasing MetS components. Lepetin and PAI on the other hand were associated with higher odds of MetS and with increasing number of MetS components. Taken together, this data highlights some of the potential role these metabolic markers play in development of MetS and CVD as well as their diagnostic value in this population.

\section{HsCRP, PAI-1 and Leptin Association with Metabolic Risk Factors and MetS}

MetS is defined by different health organizations as a cluster of metabolic risk factors that constitute an increased risk for developing T2D and CVD [20] [21]. Central obesity, dislypidemia hypertension and hyperglycemia are key components in the definition of MetS $[21,22]$. MetS is also characterized by a chronic low grade inflammation condition [20,23]. Current definitions of MetS lack a component that measures inflammation status. HsCRP has been suggested as a sensitive marker that is predictive of MetS as well as development of cardiovascular problems [20,22-24]. Our data showed that hsCRP correlated with all the measured risk factors and was most predictive of the development of MetS in this population. HsCRP strong association with increased number of MetS components highlights its beneficial use as prognostic marker for metabolic disorders in this population as well.

Using a wide range of adipokines our current study showed that women possessed higher circulating levels 
Table 2 Spearman Correlation ( $\mathrm{p}$-value) of Metabolic Markers with cardio-metabolic risk factors

\begin{tabular}{|c|c|c|c|c|c|c|c|c|c|c|c|}
\hline Markers & BMI & WC & SBP & DBP & FBG & HbA1c & HOMA-IR & TC & HDL & LDL & TG \\
\hline Leptin (ng/ml) & $0.48(<.0001)$ & $0.45(<.0001)$ & $0.01(0.9074)$ & 0.08 (0.1239) & $-0.02(0.6386)$ & $-0.1(0.0614)$ & $2(<.0001)$ & $0.02(0.7071)$ & $-0.01(0.8035)$ & $0.02(0.7113)$ & $0.10(0.0687)$ \\
\hline $\mathrm{Pa}$ & 2) & ) & 0.11 (0.0318) & $0.10(\mathbf{0 . 0 4 9 1 )}$ & $0.06(0.2188)$ & $-0.1(0.0872)$ & ) & ) & 9) & ) & 1) \\
\hline Adiponectin ( $\mu \mathrm{g} / \mathrm{ml})$ & $-0.26(<.0001)$ & $-0.21(<.0001)$ & $-0.13(\mathbf{0 . 0 1 6 5 )}$ & $-0.17(0.2107)$ & $-0.22(<.0001)$ & $-0.18(\mathbf{0 . 0 0 0 7 )}$ & 0001) & $-0.08(0.1212)$ & $0.33(<.0001)$ & $0.0509)$ & $-0.28(<.0001)$ \\
\hline Visfatin (ng/ml) & $0.10(0.0663)$ & $0.02(0.7477)$ & $0.01(0.8272)$ & $-0.01(0.9019)$ & $0.17(\mathbf{0 . 0 0 1 0})$ & $-0.01(0.8821)$ & $0.20(\mathbf{0 . 0 0 0 1 )}$ & $0.13(\mathbf{0 . 0 1 3 8 )}$ & $-0.13(\mathbf{0 . 0 1 8 4})$ & $0.13(\mathbf{0 . 0 1 7 9 )}$ & $0.12(\mathbf{0 . 0 1 9 5 )}$ \\
\hline Adpisin (ng/ml) & $0.33(<.0001)$ & 0001) & $0.03(0.6119)$ & $0.10(0.2710)$ & $-0.12(\mathbf{0 . 0 2 0 7 )}$ & $-0.15(\mathbf{0 . 0 0 4 8 )}$ & 0.02 & $-0.08(0.1235)$ & $-0.05(0.2055)$ & $-0.10(0.0523)$ & $0.08(0.1175)$ \\
\hline Resistir & $-0.07(0.1751)$ & $-0.06(0.2596)$ & $-0.11(\mathbf{0 . 0 4 4 8 )}$ & $-0.14(\mathbf{0 . 0 0 8 2})$ & $-0.14(\mathbf{0 . 0 0 7 4 )}$ & $-0.09(0.0776)$ & $-0.14(\mathbf{0 . 0 0 0 6 )}$ & $-0.06(0.28)$ & $-0.05(0.3937)$ & $-0.04(0.4869)$ & $-0.01(0.8508)$ \\
\hline hsCRP ( $\mu \mathrm{g} / \mathrm{ml})$ & $0.50(<0.0001)$ & $0.46(<\mathbf{0 . 0 0 0 1 )}$ & 0.14 (0.0085) & 0.16 (0.0029) & 0.13 (0.0148) & 0.19 (0.0004) & $0.36(<0.0001)$ & $0.15(\mathbf{0 . 0 0 5 5 )}$ & $-0.18(\mathbf{0 . 0 0 0 8 )}$ & $0.15(\mathbf{0 . 0 0 5 0 )}$ & 0.15 (0.0046) \\
\hline
\end{tabular}

Values are age-sex adjusted Sperman partial correlation coefficients and $P$ values for correlations of metabolic markers and cardiovascular disease risk factors. 
Table 3 Multiple logistic regression models for MetS in relation to metabolic markers

\begin{tabular}{lcccc}
\hline Biomarkers & T1 & T2 & T3 & P-trend \\
& Reference & OR (95\% Cl) & O5\% Cl) & \\
\hline Adiponectin $(\mu \mathrm{g} / \mathrm{ml})$ & 1 & $0.38(0.22-0.67)$ & $0.22(0.12-0.40)$ & $<.0001$ \\
Leptin $(\mathrm{ng} / \mathrm{ml})$ & 1 & $2.71(1.46-5.02)$ & $3.02(1.47-6.19)$ & 0.0029 \\
PAl-1 $(\mathrm{ng} / \mathrm{ml})$ & 1 & $1.81(1.06-3.09)$ & $2.52(1.45-4.35)$ & 0.0037 \\
Visfatin $(\mathrm{ng} / \mathrm{ml})$ & 1 & $1.01(0.60-1.70)$ & $1.13(0.66-1.92)$ & 0.8860 \\
Adipsin $(\mu \mathrm{g} / \mathrm{ml})$ & 1 & $1.17(0.69-1.97)$ & $1.48(0.87-2.54)$ & 0.3528 \\
Resistin $(\mathrm{ng} / \mathrm{ml})$ & 1 & $1.48(0.86-2.55)$ & $1.06(0.62-1.81)$ & 0.3015 \\
hsCRP $(\mu \mathrm{g} / \mathrm{ml})$ & 1 & $3.21(1.85-5.58)$ & $4.26(2.39-7.59)$ & $<0.0001$ \\
\hline
\end{tabular}

The MetS models adjusted for age, and gender.

Tertile values are expressed as:

Adiponectin: T1 (<10.0; $\mathrm{n}=127), \mathrm{T} 2(10.0-16.41 ; \mathrm{n}=127)$, and T3 (>16.41; $\mathrm{n}=125)$; Leptin: T1 $(<3.27 ; \mathrm{n}=128), \mathrm{T} 2(3.27-7.23 ; \mathrm{n}=126)$, and T3 (>7.23; $\mathrm{n}=125)$;

Pai-1: T1 (<5.58; $n=129)$, T2 (5.58 - 8.00; $n=126)$, and T3 (>8.00; $n=124)$; Visfatin: T1 (2.43; $n=129), T 2(2.43-3.79 ; n=126)$, and T3 (>3.79; $n=124) ;$ Adipsin:

T1 < (1.28; $n=127), T 2(1.28-1.65 ; n=126)$, and T3 (>1.65; $n=126)$. Resistin: T1 $(<2.35 ; n=129), T 2(2.35-3.40 ; n=125)$, and T3 (>3.40; $n=125) ;$ hsCRP: T1 (<1.71; $n=130)$, T2 (1.71 - 5.12; $n=125), T 3(>5.12 ; n=124)$.

of leptin, PAI-1 and adiponectin. Even though all of these markers showed a significant difference, it was highest for leptin at almost three folds followed by adiponectin at 1.6 fold difference. This difference in leptin level for example is consistent with levels reported in other studies such as Zuo et al., reported that men had $1.45 \mathrm{ng} / \mathrm{ml}$ compared to $8.32 \mathrm{ng} / \mathrm{ml}$ in women [25]. This difference can be explained by the difference in sex hormones especially in women as a result of menopause which reduces estrogen production a factor that has been shown to lead to obesity in women [26]. Consistent with data reported in literature for other populations, leptin showed positive association with BMI and HOMA-IR.

PAI-1 and adiponectin were remarkably associated with seven and eight of the studied risk factors respectively. PAI-1 is a serine protease inhibitor that plays an important role in fibrinolysis due to its inhibition of plasminogen activation [27]. Elevated blood levels of PAI-1 have been linked to high reoccurrence events of myocardial infarction ([28-30]), Atherosclerosis [31] and MetS. The positive association of PAI-1 with all of the risk factors, except for HDL, is in agreement with literature [12]. In accordance to our data, PAI-1 has been shown to positively correlate with atherosclerosis risk factors such as obesity, hyperinsulinemia and hypertriglyceridemia [32,33]. In general, PAI-1 positively associates with MetS and its components in our study. Other studies have shown that PAI-1 level are reduced in response to interventional therapies that leads to reduction in MetS components such as insulin resistance or weight reduction [34]. Thus, the predictive ability of PAI-1 for CVD diminishes after adjusting for MetS components. This suggests that MetS is a prerequisite to high PAI-1 blood circulating level [12]. It can also explain the lack of association with as many markers in the multivariate analysis in our population.

\section{Adiponectin, a cardio-protective adipokine}

Adiponectin on the other hand associated with most CVD risk factors at the univariate and multivariate level. It associated with six of the risk factors showing the strength of this marker in predicting CVD risk. We also showed that decreasing concentration of adiponectin associated with an increasing number of CVD risk factors particularly in women highlighting the gender difference. The importance of adiponectin in CVD is well documented as its plasma level has been shown to be attenuated by cardiac pathologies such as coronary artery disease [35,36], hypertension [37] and myocardial infarction [38]. Further, low plasma levels of adiponectin are associated with obesity, T2D and MetS which are main CVD risk factors [39]. Adiponectin is believed to be a cardio-protective cytokine due to its insulin sensitizing, anti-inflammatory and antiatherogenic properties $[11,40]$. In Human, a reported single nucleotide polymorphism is associated with a reduction in adiponectin plasma levels leaving individuals with these mutations predisposed to insulin resistance [41]. Iindividuals carrying this mutation were highly susceptible to hypertension and coronary artery disease supporting the protective role this protein plays [42].

\section{Adipsin, visfatin and resistin association with metabolic markers}

Our data sheds light on the association between visfatin and adipsin with CVD risk factors in Arab population. No independent association between BMI and visfatin was observed. Association between obesity and visfatin has been contested with some studies showing positive correlation with obesity [43] while others failed to show any correlation [44]. One of the factors suggested for this discrepancy was ethnicity [45]. The fact that we show no association between visfatin and BMI emphasizes 

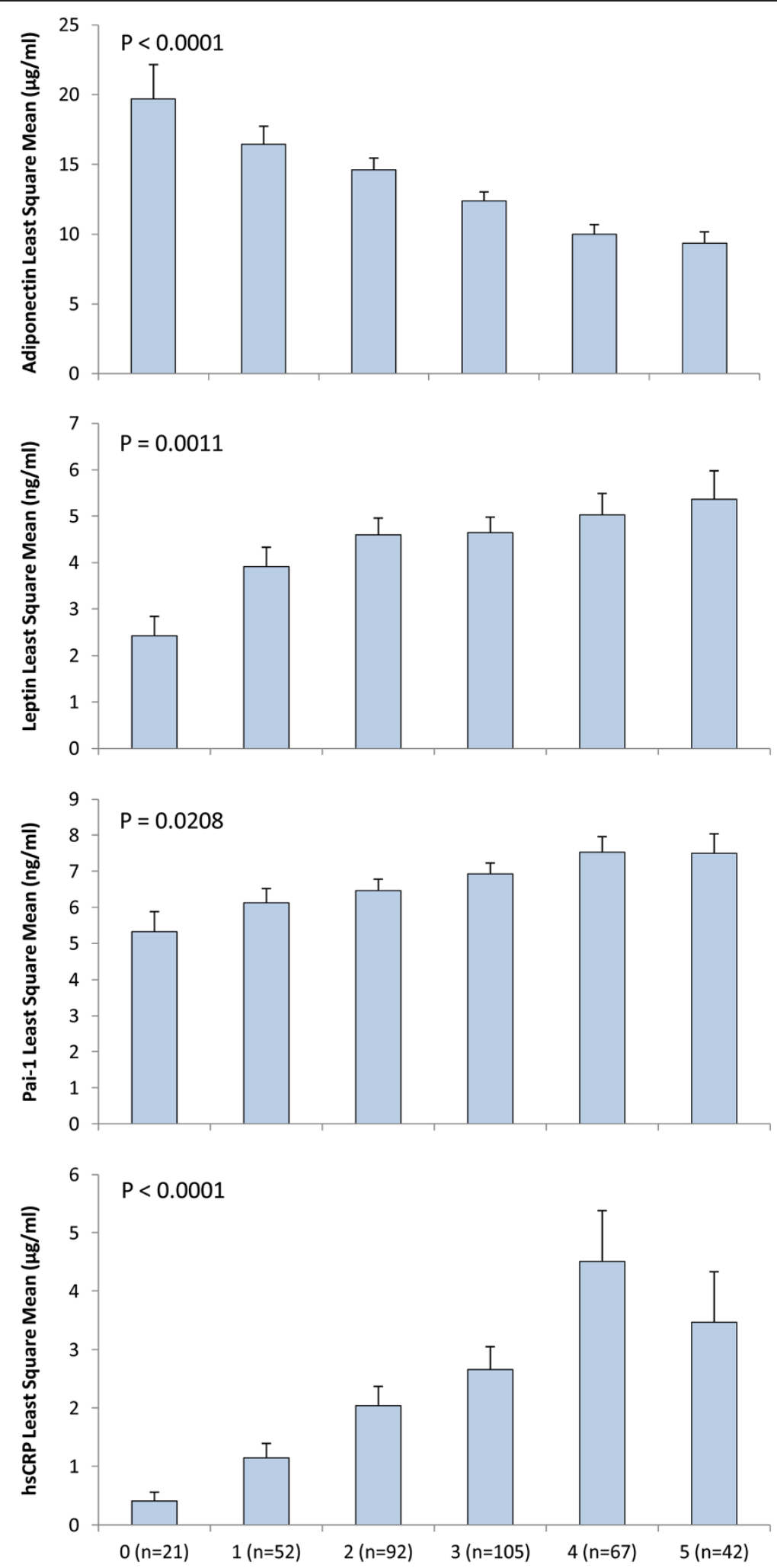

Figure 1 Age-gender adjusted least square means of concentrations of adiponectin, leptin, and PAl-1 and hsCRP according to the number of MetS components. 
the importance of ethnic variations and establishing the association between the different biomarkers in different ethnicities.

Adipsin on the other hand is a serine protease that has been shown to be upregulated in obesity. It is involved in triglyceride metabolism through the cleavage of complement factor $\mathrm{C} 3$ to $\mathrm{C} 3 \mathrm{a}$ that stimulates TG production in adipose tissue [46]. Maresh et al. showed that adipsin was upregulated in a type 1 diabetes model possibly to compensate for the increased fat utilization in insulindeficient animals [46]. Our data shows a trend of increased adipsin production in subjects with higher BMI and WC that is consistent with the known function of adipsin.

Resistin is another adipokines that was found to be increased in a diet induced obesity mouse model, as well as genetically modified diabetic and obese mouse models [47]. Resistin was also found to be a mediator of insulin resistance in rodents. Unlike rodents, resistin was predominantly expressed in monocytes and macrophages [47]. Even though, resistin was associated with obesity and insulin resistance in rodents, human data is conflicting in this regard. Some studies show association with obesity and insulin resistance while others do not show any association or negative association [47-49]. Our data shows negative association between resistin and HOMAIR, highlighting the importance of ethnic studies to better understand the function of these metabolic markers.

\section{Ethnicity and metabolic markers}

Difference in the level of various metabolic markers between different ethnic groups is well documented and is suggested as a main reason for the discrepancies reported in different studies [14-17,50-52]. For example, Caucasians have a higher level of adiponectin than other ethnicities such as Asians or African Americans [13,53]. In a multiethnic study, Morimoto et al. reported significant ethnic differences in the level of leptin, adiponectin, IL-6 and CRP between Caucasians, Japanese Americans, Latinos, African Americans and Native Hawaiians [17]. TNF- $\alpha$ on the other hand was the only biomarker that did not show any significant difference [17]. This ethnic difference in the plasma level of metabolic markers is also reflected on the association between these markers and various risk factors $[16,45]$. For example, Sulistyoningrum et al. showed that decrease in adiponectin level was associated with greater increase in insulin resistance as measured by HOMA-IR in Aboriginals, Chinese, and South Asians compared to Europeans [16].

Available data regarding the level of metabolic markers in the Arab population are scarce. Therefore, this study represents an important milestone in understanding the role of these metabolic markers in Arabs. On the other hand, studies linking various metabolic markers to the genetic background and comparing Arabs to other ethnicities are also scarce. However; Genetic variation in adiponectin and its association with metabolic disorders is one of the well studied markers in Arabs [54-57]. For example, Mtiraoui et al. reported association between adiponectin single nucleotide polymorphisms and T2D in Tunisian Arabs [56]. In another study, Zadjali et al. showed that rs266729 in the adiponectin gene was associated with traits defining obesity in Arab population [54]. As a result, such studies looking at the association between metabolic markers genetic variants and metabolic disorders in Arabs compared to other ethnicities will be crucial to better understand the ethnic variation in this ethnicity.

\section{Study strengths and limitations}

The strength of the current study is the fact that it comprehensively investigates the correlation between the CVD risk factors and adipokines in Arab population. It also highlights the importance of hsCRP in predicting MetS and potential use as a prognostic marker for increased risk of T2D and CVD. Nonetheless, we have a few limitations in this study that can be overcome in future studies. The first one is the lack of comparison with other populations especially Caucasians to establish the level of adipokines in Arabs to a well studied population. Establishing such a cohort will be a difficult task to do in Kuwait where percentage of Caucasians is limited. The second limitation regarding the study design, the cross-sectional design used here makes it impossible to determine any causal relationship between circulation levels of adipokines and CVD. It would also be important to study the effect of nutrients in future studies as they have been shown to modulate adipokines as recently shown by Juanola-Falgarona et al. [58].

\section{Conclusions}

In conclusion, this study is one of the first studies to investigate the association of metabolic biomarkers level with CVD risk factors and MetS in Arab population. Our data demonstrated the positive association between hsCRP, leptin and PAI-1 with increased number of CVD risk factors, MetS and MetS components. We also showed that adipsin was positively correlating with BMI while visfatin showed no significant correlation with BMI; both proteins did not correlate with MetS components in this population. On the other hand, adiponectin was negatively associated with many of the CVD risk factors and MetS components showing its beneficial role in this population as observed in other populations. In conclusion, hsCRP, leptin, PAI-1 and adiponectin show strongest association with CVD risk factors and MetS in Arabs. Our findings also emphasize the use of hsCRP as an important measure of low grade inflammation and its association with MetS. 


\section{Abbreviations}

LDL: Low Density Lipoprotein; HDL: High Density LipoproteinTG, Triglyceride; TC: Total Cholesterol; SBP: Systolic Blood Pressure; DBP: Diastolic Blood Pressure; BMI: Body Mass Index; WC: Waist Circumference; FBG: Fasting Blood Glucose; HOMA-IR: Homeostasis Model Assessment-Insulin Resistance; HbA1C: glycated Haemoglobin A1c; CVD: Cardiovascular Diseases; T2D: Type 2 Diabetes; hsCRP: High sensitivity C-Reactive Protein; PAI-1: Plasminogen Activator Inhibitor; MetS: Metabolic Syndrome; OR: Odd Ratio; Cl: Confidence Interval.

\section{Competing interests}

The authors declare that they have no competing interests.

\section{Authors' contributions}

MA: Data analysis and wrote the manuscript. KB: Conception of the study. NE: Conception \& design of the study, handled data analysis and interpretation, and wrote the manuscript. All authors read and approved the final manuscript

\section{Acknowledgments}

We would like to thank our study team for their efforts and excellent work. We are grateful to the Biochemistry and Molecular Biology Unit members, Clinical Laboratory and the Tissue Bank Core Facility at DDI for their contribution in performing the biochemical profile analysis and handling samples, respectively. We are also indebted to Kuwait Foundation for the Advancement of Sciences (KFAS) for financial support of this research project (RA-2010-004).

Dr. Elkum, the study principal investigator, is the guarantor of this work and as such, had full access to all the data in the study and takes responsibility for the integrity of the data and the accuracy of the data analysis.

Received: 17 February 2014 Accepted: 3 April 2014

Published: 9 April 2014

\section{References}

1. Go AS, Mozaffarian D, Roger VL, Benjamin EJ, Berry JD, Borden WB, Bravata DM, Dai S, Ford ES, Fox CS, Franco S, Fullerton HJ, Gillespie C, Hailpern SM, Heit JA, Howard VJ, Huffman MD, Kissela BM, Kittner SJ, Lackland DT, Lichtman JH, Lisabeth LD, Magid D, Marcus GM, Marelli A, Matchar DB, McGuire DK, Mohler ER, Moy CS, Mussolino ME, et al: Heart disease and stroke statistics-2013 update: a report from the American Heart Association. Circulation 2013, 127(1):e6-e245.

2. Mattu HS, Randeva HS: Role of adipokines in cardiovascular disease. J Endocrinol 2013, 216(1):T17-T36.

3. Mottillo S, Filion KB, Genest J, Joseph L, Pilote L, Poirier P, Rinfret S, Schiffrin EL, Eisenberg MJ: The metabolic syndrome and cardiovascular risk a systematic review and meta-analysis. J Am Coll Cardio/ 2010, 56(14):1113-1132.

4. Ballantyne CM, Hoogeveen RC, Bang H, Coresh J, Folsom AR, Chambless LE, Myerson M, WU KK, Sharrett AR, Boerwinkle E: Lipoprotein-associated phospholipase $\mathrm{A} 2$, high-sensitivity $\mathrm{C}$-reactive protein, and risk for incident ischemic stroke in middle-aged men and women in the Atherosclerosis Risk in Communities (ARIC) study. Arch Intern Med 2005, 165(21):2479-2484

5. Downs JR, Clearfield M, Weis S, Whitney E, Shapiro DR, Beere PA, Langendorfer A, Stein EA, Kruyer W, Gotto AM Jr: Primary prevention of acute coronary events with lovastatin in men and women with average cholesterol levels: results of AFCAPS/TexCAPS. Air Force/Texas Coronary Atherosclerosis Prevention Study. JAMA 1998, 279(20):1615-1622.

6. Alberti KG, Zimmet P, Shaw J: The metabolic syndrome-a new worldwide definition. Lancet 2005, 366(9491):1059-1062.

7. Yudkin JS, Juhan-Vague I, Hawe E, Humphries SE, di Minno G, Margaglione M, Tremoli E, Kooistra T, Morange PE, Lundman P, Mohamed-Ali V, Hamsten A: Low-grade inflammation may play a role in the etiology of the metabolic syndrome in patients with coronary heart disease: the HIFMECH study. Metabolism 2004, 53(7):852-857.

8. Wozniak SE, Gee LL, Wachtel MS, Frezza EE: Adipose tissue: the new endocrine organ? A review article. Dig Dis Sci 2009, 54(9):1847-1856.

9. Rega-Kaun G, Kaun C, Wojta J: More than a simple storage organ: Adipose tissue as a source of adipokines involved in cardiovascular disease. Thromb Haemost 2013, 110(4):641-650.
10. Fain JN: Release of inflammatory mediators by human adipose tissue is enhanced in obesity and primarily by the nonfat cells: a review. Mediators Inflamm 2010, 2010:513948.

11. Ouchi N, Walsh K: Adiponectin as an anti-inflammatory factor. Clin Chim Acta 2007, 380(1-2):24-30.

12. Alessi MC, Juhan-Vaque I: PAl-1 and the metabolic syndrome: links, causes, and consequences. Arterioscler Thromb Vasc Biol 2006, 26(10):2200-2207.

13. Pereira RI, Wang CC, Hosokawa P, Dickinson LM, Chonchol M, Krantz MJ, Steiner JF, Bessesen DH, Havranek EP, Long CS: Circulating adiponectin levels are lower in Latino versus non-Latino white patients at risk for cardiovascular disease, independent of adiposity measures. BMC Endocr Disord 2011, 11:13.

14. Khan UI, Wang D, Sowers MR, Mancuso P, Everson-Rose SA, Scherer PE, Wildman RP: Race-ethnic differences in adipokine levels: the Study of Women's Health Across the Nation (SWAN). Metabolism 2012 61(9):1261-1269.

15. Chin KH, Sathyasurya DR, Abu Saad H, Jan Mohamed HJ: Effect of ethnicity, dietary intake and physical activity on plasma adiponectin concentrations among malaysian patients with type 2 diabetes mellitus. Int I Endocrinol Metab 2013, 11(3):167-174.

16. Sulistyoningrum DC, Gasevic D, Lear SA, Ho J, Mente A, Devlin AM: Total and high molecular weight adiponectin and ethnic-specific differences in adiposity and insulin resistance: a cross-sectional study. Cardiovasc Diabetol 2013, 12:170.

17. Morimoto Y, Conroy SM, Ollberding NJ, Kim Y, Lim U, Cooney RV, Franke AA, Wilkens LR, Hernandez BY, Goodman MT, Henderson BE, Kolonel LN, Le Marchand L, Maskarinec G: Ethnic differences in serum adipokine and C-reactive protein levels: the multiethnic cohort. Int J Obes (Lond) 2014 doi:10.1038/ijo.2014.25.

18. Hajat C, Harrison O, Al Siksek Z: Weqaya: a population-wide cardiovascular screening program in Abu Dhabi, United Arab Emirates. Am J Public Health 2012, 102(5):909-914.

19. Alberti KG, Eckel RH, Grundy SM, Zimmet PZ, Cleeman Jl, Donato KA, Fruchart JC, James WP, Loria CM, Smith SC Jr: Harmonizing the metabolic syndrome: a joint interim statement of the International Diabetes Federation Task Force on Epidemiology and Prevention; National Heart, Lung, and Blood Institute; American Heart Association; World Heart Federation; International Atherosclerosis Society; and International Association for the Study of Obesity. Circulation 2009, 120(16):1640-1645.

20. Santaniemi M, Ukkola O, Malo E, Bloigu R, Kesaniemi YA: Metabolic syndrome in the prediction of cardiovascular events: The potential additive role of hsCRP and adiponectin. Eur J Prev Cardiol 2013. doi:10.1177/2047487313494028.

21. Ford ES, Schulze MB, Pischon T, Bergmann MM, Joost HG, Boeing $H$ : Metabolic syndrome and risk of incident diabetes: findings from the European Prospective Investigation into Cancer and Nutrition-Potsdam Study. Cardiovasc Diabetol 2008, 7:35.

22. Kelliny C, William J, Riesen W, Paccaud F, Bovet P: Metabolic syndrome according to different definitions in a rapidly developing country of the African region. Cardiovasc Diabetol 2008, 7:27.

23. Chiu FH, Chuang CH, Li WC, Weng YM, Fann WC, Lo HY, Sun C, Wang SH: The association of leptin and C-reactive protein with the cardiovascular risk factors and metabolic syndrome score in Taiwanese adults. Cardiovasc Diabetol 2012, 11:40.

24. Lu B, Zhang S, Wen J, Yang Y, Yang Z, Zhang Z, Wang X, Hu R: The New Unified International Diabetes Federation/American Heart Association/ National Heart, Lung, and Blood Institute Metabolic Syndrome definition: does it correlate better with C-reactive protein in Chinese patients diagnosed with type 2 diabetes? J Int Med Res 2010, 38(6):1923-1932.

25. Zuo H, Shi Z, Yuan B, Dai Y, Wu G, Hussain A: Association between serum leptin concentrations and insulin resistance: a population-based study from China. PLoS One 2013, 8(1):e54615.

26. Meyer MR, Clegg DJ, Prossnitz ER, Barton M: Obesity, insulin resistance and diabetes: sex differences and role of oestrogen receptors. Acta Physiol (Oxf) 2011, 203(1):259-269.

27. Cale JM, Lawrence DA: Structure-function relationships of plasminogen activator inhibitor- 1 and its potential as a therapeutic agent. Curr Drug Targets 2007, 8(9):971-981.

28. Hamsten A, de Faire U, Walldius G, Dahlen G, Szamosi A, Landou C, Blomback M, Wiman B: Plasminogen activator inhibitor in plasma: risk factor for recurrent myocardial infarction. Lancet 1987, 2(8549):3-9. 
29. Juhan-Vague I, Pyke SD, Alessi MC, Jespersen J, Haverkate F, Thompson SG: Fibrinolytic factors and the risk of myocardial infarction or sudden death in patients with angina pectoris. ECAT Study Group. European Concerted Action on Thrombosis and Disabilities. Circulation 1996, 94(9):2057-2063.

30. Panahloo A, Mohamed-Ali V, Gray RP, Humphries SE, Yudkin JS: Plasminogen activator inhibitor-1 (PAl-1) activity post myocardial infarction: the role of acute phase reactants, insulin-like molecules and promoter (4G/5G) polymorphism in the PAl-1 gene. Atherosclerosis 2003, 168(2):297-304

31. Kohler HP, Grant PJ: Plasminogen-activator inhibitor type 1 and coronary artery disease. N Engl J Med 2000, 342(24):1792-1801.

32. Festa A, D'Agostino R Jr, Mykkanen L, Tracy RP, Zaccaro DJ, Hales CN, Haffner SM: Relative contribution of insulin and its precursors to fibrinogen and PAI-1 in a large population with different states of glucose tolerance. The Insulin Resistance Atherosclerosis Study (IRAS). Arterioscler Thromb Vasc Biol 1999, 19(3):562-568.

33. Juhan-Vague I, Vague P, Alessi MC, Badier C, Valadier J, Aillaud MF, Atlan C: Relationships between plasma insulin triglyceride, body mass index, and plasminogen activator inhibitor 1. Diabete Metab 1987, 13(3 Pt 2):331-336.

34. Chou YY, Sheu WH, Tang YJ, Chen YM, Liao SC, Chuang YW, Lin CS, Chen DY: Plasminogen activator inhibitor type 1 (PAl-1) is a valuable biomarker for predicting the metabolic syndrome (MS) in institutionalized elderly residents in Taiwan. Arch Gerontol Geriatr 2009, 49(Suppl 2):S41-S45.

35. Hashimoto N, Kanda J, Nakamura T, Horie A, Kurosawa H, Hashimoto T, Sato K, Kushida S, Suzuki M, Yano S, Iwai R, Takahashi H, Yoshida S: Association of hypoadiponectinemia in men with early onset of coronary heart disease and multiple coronary artery stenoses. Metabolism 2006, 55(12):1653-1657.

36. Kumada M, Kihara S, Sumitsuji S, Kawamoto T, Matsumoto S, Ouchi N, Arita Y, Okamoto Y, Shimomura I, Hiraoka H, Nakamura T, Funahashi T, Matsuzawa Y: Association of hypoadiponectinemia with coronary artery disease in men. Arterioscler Thromb Vasc Biol 2003, 23(1):85-89.

37. Ohashi K, Kihara S, Ouchi N, Kumada M, Fujita K, Hiuge A, Hibuse T, Ryo M, Nishizawa H, Maeda N, Maeda K, Shibata R, Walsh K, Funahashi T, Shimomura I: Adiponectin replenishment ameliorates obesity-related hypertension. Hypertension 2006, 47(6):1108-1116.

38. Pischon T, Girman CJ, Hotamisligil GS, Rifai N, Hu FB, Rimm EB: Plasma adiponectin levels and risk of myocardial infarction in men. JAMA 2004, 291(14):1730-1737.

39. Kawano J, Arora R: The role of adiponectin in obesity, diabetes, and cardiovascular disease. J Cardiometab Syndr 2009, 4(1):44-49.

40. Pajvani UB, Scherer PE: Adiponectin: systemic contributor to insulin sensitivity. Curr Diab Rep 2003, 3(3):207-213.

41. Hara K, Boutin P, Mori Y, Tobe K, Dina C, Yasuda K, Yamauchi T, Otabe S, Okada T, Eto K, Kadowaki H, Hagura R, Akanuma Y, Yazaki Y, Nagai R, Taniyama M, Matsubara K, Yoda M, Nakano Y, Tomita M, Kimura S, Ito C, Froguel P, Kadowaki T: Genetic variation in the gene encoding adiponectin is associated with an increased risk of type 2 diabetes in the Japanese population. Diabetes 2002, 51(2):536-540.

42. Kotani K, Saiga K, Kurozawa Y, Sakane N, Tsuzaki K, Hamada T: Adiponectin I164T gene polymorphism and the obesity-related effects on the Japanese female population. Clin Chim Acta 2007, 384(1-2):182-183.

43. Pagano C, Marin O, Calcagno A, Schiappelli P, Pilon C, Milan G, Bertelli M, Fanin $E$, Andrighetto $G$, Federspil $G$, Vettor $R$ : Increased serum resistin in adults with prader-willi syndrome is related to obesity and not to insulin resistance. J Clin Endocrinol Metab 2005, 90(7):4335-4340.

44. Zou CC, Liang L, Hong F, Fu JF, Zhao ZY: Serum adiponectin, resistin levels and non-alcoholic fatty liver disease in obese children. Endocr $J$ 2005, 52(5):519-524.

45. Saddi-Rosa P, de Oliveira CS V, Crispim F, Giuffrida FM, de Lima VC, Vieira JG, Doria A, Velho G, Reis AF: Association of circulating levels of nicotinamide phosphoribosyltransferase (NAMPT/Visfatin) and of a frequent polymorphism in the promoter of the NAMPT gene with coronary artery disease in diabetic and non-diabetic subjects. Cardiovasc Diabetol 2013, 12(1):119.

46. Maresh JG, Shohet RV: In vivo endothelial gene regulation in diabetes. Cardiovasc Diabetol 2008, 7:8

47. Lee SE, Kim HS: Human resistin in cardiovascular disease. J Smooth Muscle Res 2012, 48(1):27-35.

48. Westerink J, Visseren FL: Pharmacological and non-pharmacological interventions to influence adipose tissue function. Cardiovasc Diabetol 2011, 10(1):13.
49. Mirrakhimov AE: Chronic obstructive pulmonary disease and glucose metabolism: a bitter sweet symphony. Cardiovasc Diabetol 2012, 11:132.

50. Mente A, Razak F, Blankenberg S, Vuksan V, Davis AD, Miller R, Teo K, Gerstein $\mathrm{H}$, Sharma AM, Yusuf S, Anand SS: Ethnic variation in adiponectin and leptin levels and their association with adiposity and insulin resistance. Diabetes Care 2010, 33(7):1629-1634.

51. Silha JV, Nyomba BL, Leslie WD, Murphy LJ: Ethnicity, insulin resistance, and inflammatory adipokines in women at high and low risk for vascular disease. Diabetes Care 2007, 30(2):286-291.

52. Hulver MW, Saleh O, MacDonald KG, Pories WJ, Barakat HA: Ethnic differences in adiponectin levels. Metabolism 2004, 53(1):1-3.

53. Gardener H, Crisby M, Sjoberg C, Hudson B, Goldberg R, Mendez AJ, Wright CB, Rundek T, Elkind MS, Sacco RL: Serum adiponectin in relation to race-ethnicity and vascular risk factors in the Northern Manhattan Study. Metab Syndr Relat Disord 2013, 11(1):46-55.

54. Zadjali F, Al-Yahyaee S, Hassan MO, Albarwani S, Bayoumi RA: Association of adiponectin promoter variants with traits and clusters of metabolic syndrome in Arabs: family-based study. Gene 2013, 527(2):663-669.

55. Al-Daghri NM, Al-Attas OS, Alokail MS, Alkharfy KM, Hussain T, Yakout S, Vinodson B, Sabico S: Adiponectin gene polymorphisms (T45G and G276T), adiponectin levels and risk for metabolic diseases in an Arab population. Gene 2012, 493(1):142-147.

56. Mtiraoui N, Ezzidi I, Turki A, Chaieb A, Mahjoub T, Almawi WY: Singlenucleotide polymorphisms and haplotypes in the adiponectin gene contribute to the genetic risk for type 2 diabetes in Tunisian Arabs. Diabetes Res Clin Pract 2012, 97(2):290-297.

57. Rizk NM, El-Menyar A, Marei I, Sameer M, Musad T, Younis D, Farag F, Basem N, Al-Ali K, Al Suwaidi J: Association of adiponectin gene polymorphism (+T45G) with acute coronary syndrome and circulating adiponectin levels. Angiology 2013, 64(4):257-265.

58. Juanola-Falgarona M, Salas-Salvado J, Estruch R, Portillo MP, Casas R, Miranda J, Martinez-Gonzalez MA, Bullo M: Association between dietary phylloquinone intake and peripheral metabolic risk markers related to insulin resistance and diabetes in elderly subjects at high cardiovascular risk. Cardiovasc Diabetol 2013, 12:7.

doi:10.1186/1475-2840-13-76

Cite this article as: Abu-Farha et al.: Comprehensive analysis of circulating adipokines and hsCRP association with cardiovascular disease risk factors and metabolic syndrome in Arabs. Cardiovascular Diabetology 2014 13:76.

\section{Submit your next manuscript to BioMed Central and take full advantage of:}

- Convenient online submission

- Thorough peer review

- No space constraints or color figure charges

- Immediate publication on acceptance

- Inclusion in PubMed, CAS, Scopus and Google Scholar

- Research which is freely available for redistribution
C BioMed Central 